\title{
A descentralização de distribuição de medicamentos de uso contínuo das Unidades Básicas de Saúde - UBS em parceria com o programa "Aqui tem Farmácia Popular"
}

\author{
Arildo GUADAGNINI ${ }^{(1)}$ \\ Samara Jamile MENDES ${ }^{(1)}$ \\ ${ }^{(1)}$ Faculdade de Saúde Pública, Universidade de São Paulo - USP, São Paulo, SP, Brasil.
}

Recebido: 28 jan 2019 Aceito: 10 fev 2019

Autor de correspondência: arildoguadagnini@yahoo.com.br Conflito de interesses: Os autores declaram não haver nenhum interesse profissional ou pessoal que possa gerar conflito de interesses em relação a este manuscrito.

\section{Resumo}

O programa "Aqui tem Farmácia Popular" foi criado com o objetivo de atender a população, dispensando medicamentos de uso contínuo para o tratamento de doenças crônicas. O programa "Aqui tem Farmácia Popular" cumpre uma das principais diretrizes da política nacional de Assistência Farmacêutica (CNS $n^{\circ}$ 338/2004) e deve ser defendido pelo ministério da saúde, ampliando cada vez mais em todo o território nacional. Criado em 13 de abril de 2004, por meio da Lei $n^{\circ}$ 10.858, que autoriza a Fundação Oswaldo Cruz - FIOCRUZ a disponibilizar medicamentos mediante ressarcimento, o programa "Farmácia Popular" oferecia gratuidade dos medicamentos de doenças como asma, diabetes e hipertensão em unidades de farmácias próprias. Durante todo esse período, o programa foi ampliado e em 2006 passou para as redes de farmácias privadas, criando um vínculo entre governo e estabelecimentos, passando a se chamar "Aqui tem Farmácia Popular". O programa passou a oferecer os medicamentos que já eram fornecidos anteriormente para asma, diabetes e hipertensão e ainda contraceptivos, fraldas geriátricas para pacientes que sofrem de incontinência, medicamentos para dislipidemia, rinite, osteoporose, glaucoma e Parkinson. A partir de 2011, o Programa passa a disponibilizar os medicamentos indicados para o tratamento da hipertensão e do diabetes sem custos para os usuários. Esta campanha denomina-se "Saúde Não Tem Preço" (SNTP). A Portaria 184/2011, assinada em 03 de fevereiro de 2011, determina que, a partir do dia 14 de fevereiro, todas as farmácias da Rede Própria, bem como as farmácias e drogarias credenciadas do "Aqui Tem Farmácia Popular" fiquem obrigadas a praticar os preços de dispensação e os valores de referência, garantindo, assim, a gratuidade para estes medicamentos. A partir de 04 de junho, o Ministério da Saúde também passa a disponibilizar para a população, por meio do SNTP, três medicamentos para o tratamento da asma, disponíveis em oito apresentações de forma totalmente gratuita. Os medicamentos disponíveis para asma são: Brometo de Ipratrópio, Diproprionato de Beclometasona e Sulfato de Salbutamol. Objetivo: Apresentar uma discussão sobre a transferência do acesso a medicamentos das Unidades Básicas de Saúde - UBS para as farmácias credenciadas no Programa 
Aqui tem Farmácia Popular. Método: A pergunta de pesquisa foi elaborada a partir experiência de um projeto estabelecido entre uma Secretaria Municipal de Saúde e as farmácias privadas conveniadas no Programa "Aqui tem farmácia popular", em uma cidade do interior do estado de São Paulo. A abordagem dessa pesquisa é uma revisão narrativa, que buscará encontrar todas as informações relativas ao tema, sendo a pergunta norteadora: Qual o benefício da transferência do acesso a medicamentos das UBS para as farmácias credenciadas no programa "Aqui tem Farmácia Popular"? A busca dos descritores individualmente e através dos cruzamentos and retornaram artigos, teses e monografias em sua maior parte da base de dados Lilacs e Scielo. ((mh:("Medicamentos Essenciais")) AND (mh:("Assistência Farmacêutica")); (mh:("Medicamentos Essenciais")) AND (mh:("Programas Governamentais")); (mh:("Equidade no Acesso aos Serviços de Saude")) AND (mh:("Estrategia de saude da familia")); (mh:("Servicos de saude")) AND (mh:("Assistencia Farmaceutica")); (mh:("Centros de saude")) AND (mh:("Assistencia Farmaceutica")). A priori, selecionou-se um total de 32 artigos para análise de conteúdo e que serviriam de apoio para o embasamento teórico e análise crítica dos dados coletados ao longo do estudo. Após a leitura e análise de todos os artigos, foram elencados 12 artigos que muito se assemelham ao estudo proposto pelo autor e excluídos àqueles que apresentavam focos epidemiológicos regionais sobre o serviço de dispensação de medicamentos de uso contínuo ou ainda trabalhos que restringiam a assistência farmacêutica a uma determinada região. Por se tratar de um programa que abrange outras doenças crônicas, o autor julgou pertinente não usar esses artigos como referência. Não estão sendo considerados artigos de literatura estrangeira, por considerar as particularidades do programa implantado aqui no Brasil. Por se tratar de uma revisão da literatura, utilizando dados secundários não será necessário a obtenção do parecer do Comitê de Ética em Pesquisa. Resultados: Durante o processo de busca dos descritores, foi possível observar que o conteúdo é muito restrito relativamente ao assunto Programa Farmácia Popular. Dos artigos incluídos, a maioria fala sobre obtenção de medicamentos para o tratamento de doenças crônicas, medicamentos essenciais, aquisição de medicamentos genéricos por municípios de médio porte, prática de assistência farmacêutica no Sistema Único de Saúde - SUS. Foram publicados entre os anos de 2007 e 2018, período esse que compreende todo o processo de implantação e ampliação do programa em território nacional. A transferência do acesso a medicamentos das Unidades Básicas de Saúde para as farmácias credenciadas no Programa "Aqui tem Farmácia Popular" é um fenômeno que tem acontecido em vários municípios brasileiros. Para as farmácias credenciadas, o programa tem sido vantajoso, pois recebem o repasse do valor do medicamento pelo governo federal e tem a vantagem comercial de atrair esse público para novos negócios. Por outro lado, para o usuário do programa "Aqui tem Farmácia Popular", facilitou o acesso à retirada dos medicamentos de uso contínuo, de forma que o mesmo pode se dirigir a qualquer farmácia, próxima a sua residência, em qualquer dia, inclusive aos finais de semana e feriados e em qualquer horário. Um 
das situações da transferência do acesso está relacionada com a dispensação de medicamentos de uso contínuo (hipertensão, diabetes, asma) nas farmácias comerciais, ficando para as farmácias das Unidades Básicas de Saúde os demais medicamentos essenciais, disponibilizados na Relação Nacional de Medicamentos e nas Relações Municipais de Medicamentos. Conclusões: Considerando os dados levantados através dos artigos e o conhecimento acerca do Programa "Aqui tem Farmácia Popular", podemos afirmar que o programa tem cumprido importante papel, ao tomarmos como princípio o que determina a Política Nacional de Assistência Farmacêutica, bem como a Política Nacional de Medicamentos. Um ponto a ser destacado é a articulação do programa com as Redes de Atenção à Saúde, e sua consolidação no âmbito da Assistência Farmacêutica.

Descritores: Assistência Farmacêutica; Sistema Único de Saúde; Programas Nacionais de Saúde. 